\title{
Cystic fibrosis in Tunisian children: a review of 32 children
}

\author{
Khedija Boussetta ${ }^{1}$, Fatma Khalsi ${ }^{1}$, Yasmine Bahri ${ }^{1}$, Imen Belhadj ${ }^{1}$, Faten Tinsa ${ }^{1}$, \\ Taieb Ben Messaoud ${ }^{2}$, Samia Hamouda ${ }^{1}$
}

1. Bechir Hamza Children's Hospital of Tunis, Pediatrics Department B.
2. Bechir Hamza Children's Hospital of Tunis, Biochemestry Department.

\begin{abstract}
Background: Cystic fibrosis is rare in Tunisia.Its diagnosis requires experienced specialists. Its prognosis is poor in developing countries.

Objectives: To study the epidemiologic, clinical, genetic features and the therapeutic challenges of cystic fibrosis in Tunisian children.

Methods: Covering a period of 21 years, this retrospective study included all patients with a definite diagnosis of cystic fibrosis from the Pediatrics Department B of The Children's Hospital of Tunis.

Results: Data from 32 children (14 boys and 18 girls) were collected. The diagnosis was made during the first year of life in 28 cases. Meconium ileus was found in 5 cases, respiratory manifestations in 22 cases, chronic diarrhea in 19 cases, faltering growth in 17 cases and a pseudo Barter syndrome in 2 cases. The sweat chloride test was positive in all cases. The most frequent mutation was F508del (56\% of cases). Respiratory complications marked the outcome. Among our 32 patients, 15 patients (50\%) died at an average age of 5 years and 3 months, mainly due to respiratory failure. The mean age of the surviving patients was 5 years.

Conclusion: Cystic fibrosis prognosis is poor in our series compared to developed countries due to the longer diagnostic delay and the limited therapeutic options.

Keywords: Cystic fibrosis, children, Tunisia.

DOI: https://dx.doi.org/10.4314/ahs.v18i3.24

Cite as: Boussetta K, Khalsi F, Bahri Y, Belhadj I, Tinsa F, Messaoud TB, Hamouda S. Cystic fibrosis in Tunisian Children: a review of 32 children. Afri Health Sci. 2018;18(3): 664-670. https:// dx.doi.org/10.4314/ahs.v18i3.24
\end{abstract}

\section{Introduction}

Cystic fibrosis (CF) is a genetic disease; most definitely serious, transmitted in the autosomal recessive mode. It appears to be rare disease in the African countries. Its incidence is higher reaching 1 case / 4500 births in Europe and the USA ${ }^{1}$. Much better known in Europe and

\section{Corresponding author : \\ Fatma Khalsi \\ Bechir Hamza Children's Hospital of Tunis, Department B, University Tunis El Manar, MedecineFaculty of Tunis \\ Khalsif@gmail.com}

America, cystic fibrosis occurs in individuals with inherited two mutated CFTR genes located on the long arm of chromosome 7 and playing a fundamental role in the regulation of the epithelial chlorine channels. More than 2000 mutations of this gene have been listed, giving different phenotypic tables, the F508del mutation being the most frequent.

Chronic and progressive, cystic fibrosis manifests very early in childhood, sometimes from birth. Clinical manifestations are diverse; in its classical form, the disease is dominated by exocrine pancreatic insufficiency and chronic lung infection. The prognosis and the mortality are tightly affected by the respiratory disease ${ }^{1,2,3}$. The mortality rate reported in the American registry was 1.8\% per year while this rate was between 30 and $50 \%$ in developing countries ${ }^{2,3}$. 
In Tunisia, cystic fibrosis was long considered a relatively rare condition. With the development of diagnostic facilities, several cases of cystic fibrosis have been diagnosed in recent years posing real problems of care for these children.

Thus, the increase in the number of children suffering from cystic fibrosis, the severity of this disease and the improvement in life expectancy have prompted us to carry out this work in order to:

-Study the epidemiological and clinical characteristics of cystic fibrosis.

-Report the mutations most frequently reported in our series.

-Study the treatment modalities and therapeutic difficulties encountered.

-Analyze the outcome of Tunisian patients with this disease

\section{Methods \\ Study design}

This retrospective study was carried out in child pulmonology referral unit (Children's Department B in Bechir Hamza Children's Hospital of Tunis) from 1996 to 2016. We collected all patients with a definitive diagnosis of cystic fibrosis based upon positive sweat tests (Sweat chlorine greater than $60 \mathrm{meq} / \mathrm{l}$ ) and the presence of a mutation in the homozygous state or two heterozygous mutations on the gene encoding the CFTR protein.

Several techniques were performed for genotype diagnosis: DNA extraction was from peripheral blood. Polymerase chain reaction (PCR) and polyacylamide gel electrophoresis, and reverse dot blot procedures were used to detect known point mutations. Denaturant gradient gel electrophoresis (DGGE) were used in a next step searching for the unknown point mutations that are later identified by automated sequencing on ABIprism 310. This strategy allowed us to detect 17 different mutations located on the different exons of the CFTR gene.

Nucleotide numbers are derived from cDNA CFTRsequences (GenBank accession no. NM_000492). Mutationsare named according to the numbers used in the CFTRMutation Database (http://www.genet.sickkids. on.ca/cftr/).

\section{Data collection}

Data was collected from patients' medical records. For each patient, we noted the age at first symptoms and atdiagnosis and the circumstances of the CF discovery.We registered the existence of a family history of CF.

We analysed the clinical data at diagnosis and during themonitoring as well as the results of the different investigations made. The clinical data specified the presence of recurrent or persistent upper and lower respiratorysymptoms. The radiological exploration included a chestx-ray, chest CT scan, and echocardiography. The sputum culture was carried out at diagnosis, during an acute respiratory exacerbation and/or during the monitoring. The lung function tests were performed by plethysmography. They were based on the measurement ofthe specific airway resistance for the children aged more than four and on spirometry for those aged more thanseven. The steatorrhea was assessed in the biochemical department. Determination of chloride ions in sweat was carried out in the biochemistry laboratory of the Children's Hospital of Tunis, by iontophoresis with pilocarpine. Molecular biology data were analyzed; five classes of mutations were defined based on their repercussions on synthesis, intracellular progression and protein function. All the analyzes in molecular biology were carried out in the biochemistry laboratory of the Hospital of Béchir Hamza children of Tunis. The management of the disease was also analyzed. The minimal required duration of thefollow-up was two years.

\section{Statistical analysis}

This study wascross-sectional and descriptive. The data were entered using Excel software as qualitative and quantitative values. The variables were expressed as percentagesand compared using the Chi square test. The Chi-square test associations between mortality rate and diagnostic delay and age at diagnosis were appropriate. The significance level of " $p$ " was 0.05 .

\section{Results}

The incidence of cystic fibrosis in the Pediatric department B of the Children's Hospital Béchir Hamza de Tunis was estimated at 1.5 new cases / year.Its prevalence was 0.4 per 1000 hospitalizations. The consanguinity rate was estimated at $63 \%$. Twelve patients $(40 \%)$ had a family history of infant death in a context suggestive of cystic fibrosis. Eleven patients (34.3\%) had a family history of cystic fibrosis.

The number of new cases varied according to the year with extremes ranging from 1 case to 7 new cases / year. In our series, the number of boys was 14 or $43.7 \%$ of the cases. The number of girls was 18 . The sex ratio was 
estimated at 0.77 . In our series the regions most affected by cystic fibrosis were the north and the south of the country.

Twenty-two patients $(68.7 \%)$ were under the age of 6 months at the time of diagnosis. The diagnosis of cystic fibrosis was confirmed in 28 patients $(87.5 \%)$ before the age of 1 year. The mean age at diagnosis was 8.55 months \pm 14.42 [1 month-60 months]. Clinically, in the neonatal period, six had delayed emission of meconium, defined by the absence of meconium emissions beyond 48 hours of life. Five patients $(17 \%)$ had a neonatal occlusion due to meconium ileus. One case was associated with small bowel atresia.

Beyond the neonatal period, the revealing symptoms were recurrent bronchopneumonia in 21 cases $(70 \%)$, chronic diarrhea in 19 cases (59.3\%), and faltering growth in 17 cases $(53 \%)$.

Twenty-one patients had chronic respiratory signs (70\%). The mean age of onset of respiratory symptoms was estimated at 4.3 months \pm 7.6 [1 month-36 months].This symptomatology was present before the age of 3 months in 11 cases, between the age of 3 months and 12 months in eight cases and after the age of 1 year in one case. Anemia was found in almost half of patients (53\% of cases). Six patients $(18.7 \%)$ had cholestasis. They were less than 3 months old. A pseudo-Bartter syndrome was observed in only two cases. Eight patients $(25 \%)$ had hypoproteinemia with an estimated mean value of $47.87 \mathrm{~g} / 1 \pm 7.37$ [36-57 g / 1].

The association edema-anemia-hypoproteinemia was found in two cases $(6.2 \%)$. Exocrine pancreatic insufficiency was confirmed in $30(93.7 \%)$ of 32 patients who had a dosage of steatorrhea. A cytobacteriological initial examination of sputum was practiced in all cases and isolated at least one organism in 22 cases $(68.7 \%)$. Twenty-two patients presented a primary infection with Pseudomonas aeruginosa $(68.7 \%)$ at a mean age of 41.5 months in our patients. The other types of organisms isolated were: Staphylococcus aureus in 5 cases (15.6\%), Haemophilus infuenzae in 5 cases $(15.6 \%)$ and Klebsielle Pneumonia in three cases $(9.4 \%)$. The cytobacteriological initial examination of sputum was negative in ten cases $(31.2 \%)$. The diagnosis of cystic fibrosis was confirmed by carrying out two sweat tests in most cases, coupled to molecular biology. The sweat test was practiced in all cases. It was performed only once in eight cases, twice in 21 cases and three time in two cases. In the first test, all the results were positive. The average amount of chloride salt rate in sweat was estimated at $99.35 \mathrm{mmol} / \mathrm{L} \pm 24.38$ [60-161 mmol / L].During the second test, it was estimated at 104.37 mmol / L \pm 21.4 [72-135]. For the molecular biology diagnosis, we extracted the DNA of the totality of patients. The technic used was the PCR method practiced in the biochemistry laboratory of the Hospital of Children Béchir Hamza of Tunis. The results of the mutations of 30 patients are available. The F508del mutation was the most frequent (56\% of the alleles). It was homozygous in 15 cases (46.8\%) and heterozygous in 4 cases $(12.5 \%)$. Molecular biology in parents and siblings was done in 4 cases, they were all heterozygotes for F508 del mutation. A neonatal screening from an index case revealed the disease early in a patient.

The E1104X mutation occupies the secondposition in our series after F508del (7\% of the mutated alleles) followed by the G542X mutation and $711+1 \mathrm{G}->\mathrm{T}(5 \%$ each) then the G85E mutation (3\%) and the W1282X mutation $(3 \%)$.

From a therapeutic point of view, the management of meconium ileus was surgical in all cases. A curative antibiotherapy, was administered to manage bronchopulmonary exacerbation. Seventeen patients (53\%) were considered chronic colonized by Pseudomonas aeruginosa. They received systematic intravenous antibiotic therapy. Respiratory physiotherapy, prescribed in all cases, was done regularly.

Fourteen patients underwent aerosol therapy (43.7\%). The molecules used were the inhaled Colimycin $\AA$ prescribed in the long course in the interval of the cures intravenous in patients with chronic colonization by pseudomonas aeruginosa. Inhaled corticosteroids were prescribed in 4 cases with clinical signs of bronchial hyperreactivity. Eight patients $(25 \%)$ required long-term oxygen therapy because of a chronic respiratory failure. It was only nocturnal in five cases and nocturnal and diurnal in three cases. The mean age of long-term oxygen therapy use in our series was 73.13 months \pm 40.94 [11-136 months]. 
Non-invasive ventilation was necessary in one case and this was at the age of 14 years.No patient had a pulmonary transplantation.

Vitamin therapy was instituted in all patients with daily intake of sterogyl, Ephynal * and intra-muscular vitamin $\mathrm{K}$ during hospitalizations. Eighteen patients $(56.2 \%)$ were under poly-vitaminated syrups (Hydrosol polyvitaminin drops $*$, Alvityl *, Calvitalis *). A high dose of vitamin intake (according to guidelines)was given to five patients with low vitamin serum levels. All patients were treated by pancreatic extracts. The mean dose was estimated to be 6018.2 IU lipase / kg \pm 2200.56 [2570-10714 PubMed U / kg].Nutritional support was provided by discontinuous gavage for three patients $(9.4 \%)$. No patient was given continuous flow enteral nutrition or parenteral nutrition.

In addition, 7 patients with anicteric cholestasis $(21.9 \%)$ were treated by ursodeoxycholic acid.

$\mathrm{NaCl}$ oral supplementation was prescribed in 5 infants. This supplementation was increased during periods of heat.

The mean periodof follow-up of our patients was 61.28 months \pm 65.7 [0-20 years]. The respiratory evolution was marked by the occurrence of several episodes of acute exacerbations. On the respiratory side, the primary infection with pseudomonas aeruginosa was detected in 22 cases at an average age of 41.5 months. Chronicity was observed in 17 cases (53\%) at an average age of 5 years and 4 months. Seventeen patients were given periodic antibiotic therapy every 3 to 4 months. The mean age of these patients was 5 years, our oldest surviving patient is about 23 years old.

Complications were observed in the course of the respiratory disease with episodes of haemoptysis in five cases. Changes in respiratory function were unfavorable with the onset of chronic respiratory failure in eight cases $(25 \%)$ requiring long-term oxygen therapy at home. Fifteen patients $(46.9 \%)$ developed bronchiectasis diagnosed by thoracic CT scan. Seven patients had spirometry which showed obstructive irresversible syndrome with a mean forced expiratory volume of $68 \%$.

Hepatic involvement was marked by cirrhosis in one case $(3.1 \%)$ with esophageal varices at endoscopy. Of the 5 patients over 10 years of age, two patients $(6.2 \%)$ developed type cystic fibrosis-related diabetes. For the digestive symptoms, the outcome was marked by the restoration of a normal transit, after the placing under pancreatic extracts. Of our 24 patients followed on an average duration of 5 years and 4 months [3 months-19 years], 11 had flatering growth. This failure to thrive was severe in six cases, moderate in two cases and mild in three

cases.

Among our 32 patients, 15 patients (50\%) died at an average age of 5 years and 3 months \pm 5 years ( 3 months- 14 years and 3 months). Six deaths (40\%) occurred before age 1 year. The circumstances of death were dominated by respiratory exacerbations with acute decompensation of chronic respiratory insufficiency, observed in 10 cases.

\section{Discussion}

Cystic fibrosis is rare in African countries but severe with a long diagnostic delay since neonatal screening is not practiced.

The prevalence of cystic fibrosis is increasing worldwide. In Tunisia, cystic fibrosis was long considered a relatively rare condition. With the development of diagnostic facilities, several cases of cystic fibrosis have been diagnosed in recent years ${ }^{4}$. However, its incidence and prevalence are still unknown ${ }^{5}$.

The largest series published in Tunisia is by Messaoud et al. ${ }^{6}$, over 16 years of study (1990-2005). It covered 390 children from different regions of Tunisia. This work was carried out from the results of the sweat test as there was a centralization of the realization of this test.

In our monocentric series, we collected 32 cases of Cystic fibrosis over a 21-year period (1996-2016). The hospital prevalence was estimated at $0.4 / 1000$.

The rate of consanguinity was high in the different Arabic and Tunisian series ${ }^{7,8,9}$. In our series consanguinity was noted in 19 couples. This could be explained by the habits inherent in our socio-cultural context.

The mean age at diagnosis was 8.55 months in our series. A considerable delay in diagnosis is observed in comparison with the series of developed countries, especially after the introduction of systematic screening in the neonatal period, instituted in 2002 in France.

The average age of clinical diagnosis of cystic fibrosis, according to US data from the National Cystic Fibrosis Patient Registry, is seven months before the age of systematic neonatal screening ${ }^{10,11}$. 
In the different regions where a screening policy exists, the median age at diagnosis is four to six weeks ${ }^{12}$.

On the other hand, the average age of our patients is earlier than that reported in the series of Meherzi and Boukari. ${ }^{13,14}$.

Initial symptoms associate recurrent bronchitis with a productive, per year annual cough ${ }^{9}$. The mean age of onset of respiratory symptoms was estimated at 4.3 months \pm 7.6 [1 month-36 months] in our series.

The past decade has seen significant advances in understanding of the pathogenesis and progression of lung disease in cystic fibrosis. Pulmonary inflammation, infection and structural lung damage manifest very early in life and is prevalent among preschool children and infants, often in the absence of symptoms or signs, affects the prognosis and the quality of life of patients ${ }^{17,18}$.

The severity of the respiratory involvement is due also to the early burden of the chronic infection by the Pseudomonas aeruginosa. The mean age of colonization of Tunisian patients is earlier: 5 years and 1 month in the Chaabouni $\mathrm{M}$ and al series ${ }^{5}, 5$ years and 4 months [1-14 years] in our series, and 15.6 months Khemiri $\mathrm{M}$ and al series ${ }^{16}$. Moreover, colonization rates are higher in Tunisian patients (53\% our series, $83 \%$ in the Chaabouni series ${ }^{5}$ and $31 \%$ in the Khemiri series $\left.{ }^{16}\right)$. These differences cannot be attributed only to genetic factors, but also to environmental factors, namely the unfavorable conditions in the sanitary premises favoring transmission of cross-infection ${ }^{19}$ and the controversy over management ${ }^{20}$.

The cytobacteriological examination of sputum was performed in our series 4 times a year, even in the asymptomatic patient and during exacerbations before any antibiotic therapy. Its implementation in the course of a course of antibiotic therapy is indicated in order to evaluate the effectiveness of the treatment ${ }^{25}$.

The digestive manifestations, represented mainly by chronic diarrhea, were present in $14.6 \%$ of the cases in the French register ${ }^{15}$. On the other hand, this rate was higher in the Khatami series and in the Tunisian series (50 $\%$ in Hlioui series ${ }^{26}$ and $60 \%$ in ours). This is explained by the policy of neonatal screening and the early start of opotherapy preventing any chronic diarrhea in France.

Exocrine pancreatic insufficiency affects $50 \%$ to $89.9 \%$ of patients with cystic fibrosis ${ }^{14,27,28}$.

More than half of the newborns suffer from an exocrine pancreatic insufficiency as of the first assessment. This percentage increases towards the end of the first year of life, reaching almost $85 \%$ according to the national cystic fibrosis registry ${ }^{29}$.

In our series it involved $85 \%$ of patients.

In infants, exocrine pancreatic insufficiency may be associated with edema-anemia-hypoproteinemia. The frequency of this clinico-biological triad during cystic fibrosis varies from $5 \%$ to $19.4 \%$ of cases according to the authors ${ }^{14,30}$.

Chronic diarrhea and exocrine pancreatic insufficiency can be one of the numerous causes of malnutrition frequently seen in cystic fibrosis ${ }^{31}$. Hypotrophy was present in $12.4 \%$ of cases in the French register ${ }^{15}$ while it was revealing of the diagnosis in $88 \%$ of the cases in the kahtami series ${ }^{16}$. In the Tunisian series; hypotrophy was part of the initial clinical picture in $53 \%$ of the cases of our series.

Like the exocrine pancreatic insufficiency, endocrine pancreatic insufficiency can be seen in subsequent years to decades, usually not before the age of 10 with a prevalence of $20 \%$ in adolescents. It is associated with worselung disease, malnutrition and mortality ${ }^{32}$.

According to the basis of the mutations of the cystic fibrosis, more than 2,000 mutations of CFTR gene have been identified to date ${ }^{33}$. In 2005 , the genetic study of cystic fibrosis in Tunisia identified 17 mutations localized on different exons of the CFTR gene. The most frequent mutation was F508 del (50.7\%) followed by the mutation E1104X (16.18\%) and 3 other mutations commonly found in the Mediterranean countries (G542X, W1282X and $\mathrm{N} 1303 \mathrm{~K})^{6}$. In our series, the F508 del mutation is also predominant (56\% of alleles), followed by the E1104X mutation in four cases, both resulting in the absence of CFTR protein function and then a severe phenotype ${ }^{6}$.

Mortality in our series remains high (15 patients among 32) compared to countries where the disease is detected at birth ${ }^{34}$. The mortality rate in the American registry was $1.8 \%{ }^{2}$. Nationally, the mean age of death varies from a country to another (22 months in the series Khemiri et al1 6,5 years and 3 months in ours and 7 years in the series of Hlioui. $\mathrm{S}$ and $\mathrm{al}^{26}$. This progress can be attributed to a better knowledge of the disease and better management at the level of the pediatric hospitals generally and our department especially. Given the severity of the disease and the therapeutic difficulties, genetic counseling and prenatal diagnosis were proposed to families ${ }^{4}$. The neonatal 
screening from an index case revealed the disease early in a patient. In the series of Hlioui $\mathrm{S}$ and $\mathrm{al}^{26}$ an antenatal diagnosis was made in 9 families, the fetus was homozygous in 3 cases. The identification of new mutations should facilitate antenatal diagnosis of cystic fibrosis in Tunisia.

\section{Conclusion}

Cystic fibrosis is the most common inherited disorder in Caucasian populations, with more than 2000 cystic fibrosistransmembrane conductance regulator (CFTR) mutations presently described. The distribution of the mutations ranges widely between countries and/or ethnic groups. CF in Tunisian children is rare and severe with predominance of first classes of mutations.

Further multi-centric studies are needed to study the genotype-phenotype correlations.

In order to improve the prognosis of this disease in our region, we propose a national action plan witch aim to:

- $\quad$ Ensure better training of primary care physicians in the early diagnosis of the disease

- $\quad$ Strengthen collaboration between adult pediatricians and pneumologists to ensure continuity of quality care in adulthood and to allow for a gradual and better tolerated transition by the patient.

- $\quad$ Systematically institute a consultation for genetic counseling for parents of index cases.

- $\quad$ Create a national register for the census of children with cystic fibrosis in order to have more precise epidemiological data, in order to define the health needs at national level and to locate us at the international level.

\section{Conflict of interest}

The authors declare no conflict of interest

\section{References}

1. National Observatory of Cystic Fibrosis. Data review 2013. Overcoming cystic fibrosis and INED.

2. Cystic fibrosis foundation patient registry 2009 annual data report. Bethesda, MD, USA: Cystic Fibrosis Foundation; 2010.

3. O'Sullivan BP, Freedman SD. Cystic fibrosis. Lancet. 2009;373(9678):1891-904. PubMed
4. Sosnay PR, White TB, Farrell PM, Ren CL, Derichs $\mathrm{N}$, Howenstine MS and al. Diagnosis of Cystic Fibrosis in Nonscreened Populations. J Pediatr. 2017 Feb;181S:S52-S57.e2.

5. Chaabouni M, Krichen A, Ben Halima N, Aloulou H, Mahfoudh A, Hachicha M, et al. [Cystic fibrosis of the child]. Tunis Med. 2004;82(6):516-25. PubMed.

6. Messaoud T, Bel Haj Fredj S, Bibi A, Elion J, Ferec C, Fattoum S. Molecular epidemiology of cystic fibrosis in Tunisia. Ann Biol Clin (Paris). 2005;63(6):627-30.

7. Naguib ML, Schrijver I, Gardner P, Pique LM, Doss SS, Abu Zekry MA, et al. Cystic fibrosis detection in highrisk Egyptian children and CFTR mutation analysis. J Cyst Fibros. 2007;6(2):111-6. PubMed.

8. Belhaj R, Souissi W, Hadjfrej S, Bibi A, Messaoud T. Profile of biochemical markers in cystic fibrosis. Prospective study about 13 cases]. Tunis Med. 2011;89(6):5447. PubMed.

9. Rawashdeh M, Manal H. Cystic fibrosis in Arabs: a prototype from Jordan. Ann Trop Paediatr. 2000;20(4):283-6.

10. Fitz Simmons SC. The changing epidemiology of cystic fibrosis. J Pediatr. 1993;122(1):1-9. PubMed.

11. Green MR, Weaver LT, Heeley AF, Nicholson K, Kuzemko JA, Barton DE, et al. Cystic fibrosis identified by neonatal screening: incidence, genotype, and early natural history. Arch Dis Child. 1993;68(4):464-7. PubMed.

12. Brouard J, Lecoq I, Viel JF, Guillot M, Laurans M, Laroche D, et al. [Evaluation of diagnosis and follow-up in screened children with cystic fibrosis in Normandy]. Arch Pediatr. 2001;8 Suppl 3:603-9. Arch Pediatr. 2015;22(5 Suppl 1):5-6. PubMed.

14. Meherzi S. La mucoviscidose: Particularités cliniques, thérapeutiques et évolutives chez l'enfant du Grand Tunis. Thèse de doctorat en médecine. Tunis 2012.

15. French Cystic Fibrosis Registry - Data Review 2012 Overcoming Cystic Fibrosis and the National Institute for Demographic Studies (INED) Paris, March 2014.

16. Khatami G, Mir-Nasseri M, Seyghali F, Allah-Verdi B, Yourdkhani F. Characteristics of Patients with Cystic Fibrosis: Experience in a Large Referral Children's Hospital in Tehran, Iran. Middle East J Dig Dis. 2010;2(1):20-3. 17. Ranganathan SC1, Hall GL2, Sly PD3, Stick SM4, Douglas TA5 and al. Early Lung Disease in Infants and 
Pre-school Children with Cystic Fibrosis: What Have We Learnt and What Should We Do About It?. Am J RespirCrit Care Med. 2016 Dec 2.

18. Foong RE1,2, Rosenow T1,2, Garratt LW1,2, Hall GL. Early lung surveillance of cystic fibrosis: what have we learnt? Expert RevRespir Med. 2017 Jan;11(1):1-3

19. Ong T, Schechter M, Yang J, Peng L, Emerson J, Gibson RL and al. Socio-economic Status, Smoke Exposure, and Health Outcomes in Young Children With Cystic Fibrosis. Pediatrics. 2017 Feb;139(2).

20. Cogen JD1, Oron AP2, Gibson RL3, Hoffman LR3, Kronman MP4, Ong T3 and al. Characterization of Inpatient Cystic Fibrosis Pulmonary Exacerbations. Pediatrics. 2017 Feb;139(2).

21. Flume PA, Mogayzel PJ Jr, Robinson KA, et al; Clinical Practice Guidelines for Pulmonary Therapies Committee. Cystic fibrosis pulmonary guidelines: treatment of pulmonary exacerbations. Am J RespirCrit Care Med. 2009;180(9):802-808

22. Wagener JS, Rasouliyan L, VanDevanter DR, et al; Investigators and Coordinators of the Epidemiologic Study of Cystic Fibrosis. Oral, inhaled, and intravenous antibiotic choice for treating pulmonary exacerbations in cystic fi brosis. Pediatr Pulmonol. 2013;48(7):666-673

23. Lebecque P, Leal T, Zylberg K, Reiychler G, Bossuyt $\mathrm{X}$, Godding V. Towards zero prevalence of chronic Pseudomonas aeruginosa infection in children with cystic fibrosis. J Cyst Fibros. 2006; 5:237-244. PubMed.

24. Máiz L, Girón RM, Olveira C et al. Inhaled antibiotics for the treatment of chronic bronchopulmonary Pseudomonas aeruginosa infection in cystic fibrosis: systematic review of randomised controlled trials. Expert Opin Pharmacother. 2013;14:1135-49

25. Pin I, Bremont F, Clement A, Sardet A. [Manage- ment of pulmonary involvement in mucoviscidosis in the child]. Arch Pediatr. 2001;8Suppl 5:856s-83s.

26. Halioui-Louhaichi.S, Ben Chehida. A, Hassouna.R, Massaoud.T, BenDridi MF, Barsaoui.S and al. Cystic Fibrosis in Tunisian Children: About 33 Observations. La tunisie Medicale - 2015 ; Vol 93 ( n08 ) : 569-573.

27. De Dios Caballero J, Del Campo R, Royuela A, Sole A, Maiz L, Olveira C, et al. Bronchopulmonary infection-colonization patterns in Spanish cystic fibrosis patients: Results from a national multicenter study. J Cyst Fibros. 2015

28. Pepermans X, Mellado S, Chialina S, Wagener M, Gallardo L, Lande H, et al. Identification and frequencies of cystic fibrosis mutations in central Argentina. Clin Biochem. 2016;49(1):154-60.

29. Stafler P, Mei-Zahav M, Wilschanski M, Mussaffi H, Efrati O, Lavie M, et al. The impact of a national population carrier screening program on cystic fibrosis birth rate and age at diagnosis: Implications for newborn screening. J Cyst Fibros. 2015.

30. Najada AS, Dahabreh MM. Clinical profile of cystic fibrosis. Atypical presentation. Saudi Med J. 2010;31(2):1858.

31. Lusman S1, Sullivan J2. Nutrition and Growth in CysticFibrosis. Pediatr Clin North Am. 2016 Aug;63(4):661-78. 32. Kim RJ. Cystic Fibrosis-Related Diabetes in Children: An Update. Pediatr Ann. 2016 Sep 1;45(9):e321-6. / Akhtar Y1, Blackman SM1. Hyperglycemia in Young Children with Cystic Fibrosis. Am J RespirCrit Care Med. 2016 Oct 15;194(8):924-925.

33. Rowe SM, Miller S, Sorscher EJ. Cystic fibrosis. $N$ Engl J Med. 2005;352 (19):1992-2001. PubMed.

34. Bell SC, Bye PT, Cooper PJ et al. Cystic fibrosis in Australia: results from a data registry. Med J Aust. 2011;195:396-400. PubMed. 